\title{
Gender and the recognition of vertebral fractures
}

\author{
Brian C. Lentle \\ Department of Radiology, University of British Columbia, Vancouver, Canada \\ Correspondence to: Dr. Brian C. Lentle, Professor Emeritus. 740, 205 Kimta Rd. Victoria, British Columbia, Canada. Email: bclentle@gmail.com.
}

Provenance and Peer Review: This article was commissioned by the editorial office, Quantitative Imaging in Medicine and Surgery. The article did not undergo external peer review.

Comment on: Wáng YXJ, Che-Nordin N, Deng M, Griffith JF, Leung JCS, Kwok AWL, Leung PC, Kwok TCY. Elderly males with or without existing osteoporotic vertebral fracture have much lower future vertebral fracture risk than elderly females: the MrOS (Hong Kong) year-4 follow-up spine radiograph study. Osteoporos Int 2019;30:2505-14.

Submitted Apr 06, 2020. Accepted for publication Apr 28, 2020.

doi: 10.21037/qims.2020.04.12

View this article at: http://dx.doi.org/10.21037/qims.2020.04.12

\section{Background}

Osteoporosis is a generalized skeletal disorder characterized by decreases in bone quantity and quality, or both, leading to an increased risk of fragility (that is low trauma or low energy) fractures. With the delineation of this disease, and the recognition that it may affect both sexes, and following the demonstration by Fuller Albright that treatment with estrogens could reverse the negative calcium balance that developed in women after menopause or oophorectomy, effective treatments for osteoporosis began to emerge in the late $20^{\text {th }}$ century (1):

From a radiological ("imaging") perspective, apropos of osteoporosis, peripheral fracture recognition in general is rarely a challenge. More recently, techniques have been developed to measure bone density or mass. Not least, small aperture high resolution computed tomography and magnetic resonance imaging methods are yielding insights into bone micro-architecture and "bone quality" (2). All the more perplexing, therefore, is the fact that, despite these observations, there had been only limited evidence available for use in effectively diagnosing osteoporotic vertebral fractures (OVFs) from plain radiographs-especially as these are the most widely used tool in this context. Inevitably, as a consequence there had remained great uncertainty about their evolution and confusing data about their location and incidence as a function of gender.

\section{The tangled web we weave}

At this distance it is not clear by which criteria early radiologists made a diagnosis of vertebral fracturing, hampered as they were by the lack of a "gold standard" for diagnosis. In 1960 Simon, in discussing changes in bone shape only briefly referred to osteoporosis and that in the context of the collapse of a single vertebra (3). Apart from obvious damage to a vertebral body one early concept appears to have been that of wedge fracturingthe observation that the anterior height of a vertebra might on occasion be recognizably less than the posterior or vice versa-a finding that was apparently considered to be abnormal, and attributed to fracturing. Indeed, such wedge deformities are rarely seen in the spines of children. At a time when osteoporosis still had limited therapeutic implications, Fletcher, writing in 1947, analysed the implications of "wedge fracturing" by showing that, in military servicemen, the ratio of the anterior-to-posterior height of vertebrae in the thoraco-lumbar spine was similar to any biological measurement in having a distribution about a mean. The range extended to the degree that had become attributed to a potential fracture (4). Fletcher thus concluded that the very concept of a "wedge fracture" is suspect.

Hurxthal similarly explored vertebral measurements of wedging and biconcavity without the benefit of correlation 
Table 1 The language used to describe potential OVF

Normal
Short vertebral height
Morphometric deformities
A deformity without end-plate or cortical fractures
Genant semi-quantitative (GSQ) tool
Wedging
Quantitative abnormality
Fractures
Algorithm-Based Qualitative (ABQ)-positive lesions, mABQ-
positive lesions
Osteoporotic end-plate deformity/depression
GSQ grade with end-plate and/or cortical damage (buckling)
Qualitative abnormality

OVF, osteoporotic vertebral fracture.

with bone mineral density (BMD) (5).

However, morphometry - the application of measurements of vertebral asymmetry to diagnosis-came to dominate thinking in this context such that very many approaches to morphometry have been proposed (6-13). It is a particular irony that an important step in the evolution of morphometry was the use by Barnett and Nordin of a measurement to quantitate vertebral end-plate deformation. In doing so these investigators made no reference to, or interest in, "wedging" (6).

No morphometric diagnostic tool proposed has been subject to more than proof of concept and no testing which might justify use in clinical practice (6-13). Indeed, many authors have cautioned that morphometry is a tool of potential application in population studies but not one to be applied without reservation to clinical care $(7,12)$.

The use of morphometry for fracture diagnosis culminated in the Genant Semi-quantitative (GSQ) diagnostic scheme (14), the most widely used tool in this context. Two aspects of this tool deserve particular mention. The "semi-quantitative" constraint was used because the method involved no actual measurement but was, rather, a visual estimate by the interpreting radiologist or clinician. Also, Genant et al. did emphasize in the report the importance of recognizing end plate damage as characteristic of OVF but did not make this a part of the iconic diagnostic visual tool, which is usually used alone (14). Thus, this advice has more often been ignored in pedagogy and practice $(15,16)$. Validation of the tool never amounted to more than establishing that its use was reproducible among its proponents. The GSQ tool is, in at least one context, the currently recommended clinical technique of choice for diagnosing OVF (17), despite the reservations noted above $(7,12)$.

After examining several tools for diagnosis, Jiang et al. proposed the use of a structured morphologic or qualitative approach to fracture diagnosis: the Algorithm-Based Qualitative tool (ABQ) (18). This focuses on the recognition of vertebral end-plate damage while excluding confounders, such as Schmorl nodes. In a previous report my colleagues and I have described modifying this tool to include anterior cortical fractures which are widely accepted, and visually self-evident, as fractures (mABQ) (19).

Several recent analyses had identified the diagnostic uncertainty posed by OVF $(20,21)$ although this has had a long history (22). More recently some degree of clarity has emerged in the shape of evidence from large prospective studies. Three distinct studies from Hong Kong $(23,24)$. Rotterdam, The Netherlands (25) and Canada (19) have been reported involving a combined total of more than 17,725 men and women. All three groups of investigators showed that qualitative evidence of vertebral fracture better aligns with lower bone densities and the risk of future vertebral and non-vertebral fractures, than attempts to diagnose OVF by morphometric means. These groups of workers developed their protocols in isolation rather than collaboratively and used differing terminology (Table 1) such that, while their findings lend themselves to broad conclusions, uncertainties remain in the application of detail (13).

In addition to the classifications of vertebral fracture noted above and in Table 1, other classifications of spinal fractures also exist (26) but many relate to high-energy (typically motor vehicle accident-induced) trauma. These are often "burst" fractures and commonly associated with long-tract neurological signs. Such characteristics are very rarely seen in the low-energy trauma context typical of osteoporosis.

\section{Next steps}

While some degree of clarity has emerged in respect of OVF diagnosis, as noted above, the Hong Kong and Canadian study groups have continued to analyze their data particularly in respect of what we know of the natural history of OVF and potential differences relating to gender 
and ethnicity. Previous studies had been handicapped by the uncertainties of, and differences between, the diagnostic tools used. Thus Leidig-Bruckner et al. on one hand noted that, in a population study, there are sex differences in the validity of using morphometric criteria as an index of prevalent OVF, with differences in the rates of quantitative vertebral deformities and other such findings between the sexes ranging up to $19.2 \%$ in women and $16.6 \%$ in men (27). Previously Szulc had commented that epidemiological studies suggest that vertebral deformities in men do not increase steeply with ageing, a finding would not be typical of osteoporosis as it is observed clinically (28). Szulc further suggested that many of morphometric deformities they observed might be unrelated to osteoporosis (28). BMD also did not differ between those with and without morphometric vertebral deformities although in evaluating the vertebrae these workers did slightly increase the GSQ Grade 1 threshold for such a deformity at T6-9 (28). Szulc went so far as to suggest that the majority of morphometric vertebral deformities in elderly men might be due to previous high-energy trauma.

Lauridsen measured a random sample of vertebrae from T8 to L3. They found "anterior wedging" of vertebrae to be much commoner in men than women at T8 to L3 in a random sample of 164 spinal radiographs (29). The degree of wedging was unrelated to age and no attempt was made to relate these findings to symptomatology. Matsumoto et al. in a study using spinal magnetic resonance images made similar observations in both sexes noting that the "ratio of anterior vertical height to posterior vertical height of the vertebral body in males, thinner subjects, smokers, and subjects with abnormalities of the endplates such as a Schmorl node [were] significantly smaller ... than [in] females, fatter subjects, nonsmokers, and those without endplate abnormalities". Despite such observations these workers appeared to accept that vertebral wedging might be osteoporotic in provenance (30). Irrespective of fracture classification, Kherad, in the MrOsSweden study, found "prevalent vertebral fractures to be of low clinical relevance" in men (31).

Of particular interest, Jiang, in describing on her ABQ tool, noted that there was a counterintuitive difference between the segmental distribution in the spine between prevalent and incident fractures as diagnosed using morphometric but not morphologic criteria (18). This finding was reproduced in the Canadian (19) and Rotterdam (25) studies but not remarked upon in the comparable Hong Kong report (23).

In the index publication Wáng et al. (32) have more recently found in the Hong Kong MrOS population that "elderly males, with or without existing osteoporotic vertebral fracture, had much lower future vertebral fracture risk than elderly females". This is not surprising but is different from the Canadian experience. The CaMos group had reported in an abstract presented at 2018 meeting of the American Society for Bone and Mineral Research that although prevalent vertebral morphometric deformities (without morphologic abnormalities) were common, incident morphologic vertebral fractures occurred much more frequently than incident morphometric deformities (without morphologic abnormalities) and better predicted further incident fractures. This difference in natural history of the vertebral abnormalities was interpreted as further evidence that radiographic vertebral morphometric deformities and morphologic vertebral fractures are essentially different (33). Furthermore, osteoporosis, being characterized by reduced bone quantity and/or quality with an increased predisposition to fractures, we observed increased loss of total hip BMD over time in participants with incident mABQ vertebral fracture as might be expected. GSQ were insufficiently frequent to assess any such association (33). That our findings were somewhat different from those of Wáng et al. (32) was perhaps because of ethnic differences, while follow-up extended over a decade in the CaMos report whereas for it was only 4 years in the Wáng et al. study. In these ways the full understanding of vertebral fracture recognition still eludes us.

\section{Validation}

In the absence of a "gold standard" it is perhaps useful to summarize the criteria which have been consistently used in the analyses of vertebral fracture diagnosis (13):

* Inverse correlation with BMD [MrOS Hong Kong (23); The Rotterdam Study, The Netherlands (25); CaMos, Canada (19)].

* Correlation with vertebral fracture outcomes [MrOS Hong Kong $(23,24)$; The Rotterdam Study, The Netherlands (25); CaMos, Canada (19)].

* Correlation with non-vertebral fracture outcomes [MrOS Hong Kong (23); The Rotterdam Study, The Netherlands (25); CaMos, Canada (19)].

* Insights from biomechanical studies in general.

* Correlation with mortality (No published data.)

However, a consensus has yet to be reached as follows:

* Correlation of natural history outcomes consistent with what is known about the effects of age and 


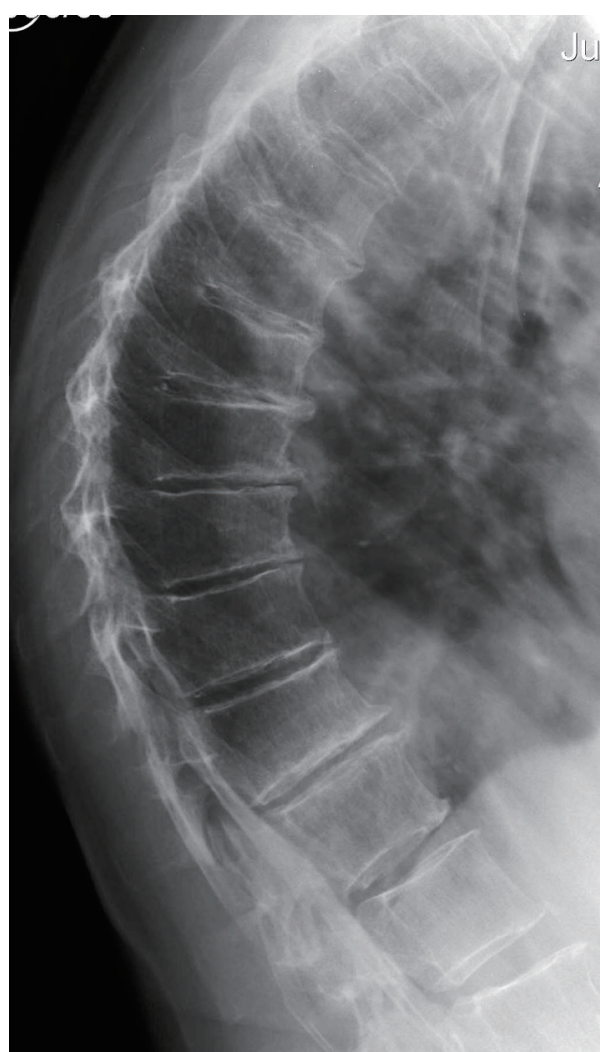

Figure 1 Thoracic spine of a 76-year-old woman. The findings (wedging, degenerative change) appear to be subject to differing interpretations which may contribute to conflicting data.

gender on osteoporosis [MrOS Hong Kong (32); CaMos, Canada (33)].

* Potential role of ethnicity which might be reflected in the radiological signs of fracture.

- Prevalent and incident fracture distribution by segment, as it correlates with biomechanical studies [The Rotterdam Study, The Netherlands (25); CaMos, Canada (19) vs. MrOS Hong Kong (32)].

To understand the niceties of the existing data is not easy. One possibility is that cultural differences exist in the way in which anomalous findings, for example in the thoracic spine, are interpreted with respect to fracturing, degenerative change and their role in scoliosis (Figure 1). The reported mis-match in the segmental distribution of vertebral fractures referred to above $(18,19,25)$ could be interpreted as an explanation for the growing suspicion of the over-diagnosis of vertebral fractures in osteoporosis. This possibility has been recognized $(28,34,35)$ and more forcibly stated by Wáng et al. (36) and is implicit in the fact that reports of vertebral fracturing increasingly disregard fractures while studies not using this strategy can produce very counter-intuitive results (37).

\section{Taxonomy}

Those groups lately working in this context and with enrollments large enough to be statistically credible [chiefly the MrOS Hong Kong group $(23,24)$; the Rotterdam group (25); the CaMos group in Canada (19)] have done so in isolation. The methods used have been comparable but not identical and, not least, the descriptive terminology used has been different (Table 1). Even normal vertebrae may be labeled as characterized by "short vertebral height" (wedged but to a smaller degree than the later GSQ classification) (38).

Jiang et al. have already found that there are differences in the frequency of morphologic signs of fracture depending, for example, on the use of the ABQ paradigm which has very stringent criteria (18). The complexity of and uncertainties (both biological and statistical) surrounding the radiographic recognition of OVF are such that answering them was never to be a simple task.

The Hong Kong group have already clarified the radiological signs of fracturing $(39,40)$ and proposed a classification of vertebral fractures and suggested a potential nomenclature (41). Perhaps it is time to build upon this. Especially so given that the increasing agreement that radiological over-diagnosis of low-grade vertebral fractures is a persisting clinical problem that threatens the credibility of the use of radiology in risk assessment $(28,34-36,42)$.

These differences are highlighted in the contrast between the more recent Hong Kong and CaMos data.

\section{What remains to be determined}

(I) In the general sense of the word, a taxonomy of vertebral fractures/deformities remains to be agreed to. The varied terminology now used to describe and define vertebral fractures (Table 1) does not serve clarity particularly for those seeking guidance free from arcane terminology and for use in day-to day radiologic practice.

(II) The diagnostic strategies used in the pivotal studies described above were similar but not identical and the derivation of an evidence-based consensus concerning diagnostic criteria is desirable. 
(III) By some means a consensus has to be arrived at by which some terms that are widely used such as "wedge fracture" are clarified as to their meaning, if any.

(IV) The relevance, if any, of the use of the descriptor "short vertebral height" (38), if it is to be used as proposed to describe a normal vertebra with some "non-threshold" degree of wedging.

(V) The natural history throughout life of morphometric vertebral deformities.

(VI) Given the above, further examinations of the impact of gender and ethnicity on the natural history of fracturing are not only desirable but necessary.

\section{Acknowledgments}

Funding: None.

\section{Footnote}

Conflicts of Interest: The author has completed the ICMJE uniform disclosure form (available at http://dx.doi. org/10.21037/qims.2020.04.12). The author has no conflicts of interest to declare.

Open Access Statement: This is an Open Access article distributed in accordance with the Creative Commons Attribution-NonCommercial-NoDerivs 4.0 International License (CC BY-NC-ND 4.0), which permits the noncommercial replication and distribution of the article with the strict proviso that no changes or edits are made and the original work is properly cited (including links to both the formal publication through the relevant DOI and the license). See: https://creativecommons.org/licenses/by-nc-nd/4.0/.

\section{References}

1. Khosla S, Hofbauer LC. Osteoporosis treatment: recent developments and ongoing challenges. Lancet Diabetes Endocrinol 2017 Nov;5:898-907.

2. Link TM. Osteoporosis imaging: state of the art and advanced imaging. Radiology 2012; 263:3-17.

3. Simon G. Principles of bone $\mathrm{X}$-ray diagnosis. 1st edition. Butterworth-Heinemann, 1960:13.

4. Fletcher GH. Anterior vertebral wedging frequency and significance. Am J Roentgenol Radium Ther 1947;57:232-8.

5. Hurxthal LM. Measurement of anterior vertebral compressions and biconcave vertebrae. Am J Roentgenol Radium Ther Nucl Med 1968;103:635-44.
6. Barnett $\mathrm{E}$, Nordin BE. The radiological diagnosis of osteoporosis: a new approach. Clin Radiol 1960;11:166-74.

7. McCloskey EV, Spector TD, Eyres KS, Fern ED, O'Rourke N, Vasikaran S, Kanis JA. The assessment of vertebral deformity: a method for use in population studies and clinical trials. Osteoporos Int 1993;3:138-47.

8. Jackson SA, Tenenhouse A, Robertson L. Vertebral fracture definition from population-based data: preliminary results from the Canadian Multicenter Osteoporosis Study (CaMos). Osteoporos Int 2000;11:680-7.

9. Guglielmi G, Diacinti D, van Kuijk C, Aparisi F, Krestan C, Adams JE, Link TM. Vertebral morphometry: current methods and recent advances. Eur Radiol 2008;18:1484-96.

10. Diacinti D, Pisani D, Barone-Adesi F, Del Fiacco R, Minisola S, David V, Aliberti G, Mazzuoli GF. A new predictive index for vertebral fractures: the sum of the anterior vertebral body heights. Bone 2010;46:768-73.

11. Diacinti D, Guglielmi G. Vertebral morphometry. Radiol Clin North Am 2010;48:561-75.

12. Griffith JF, Adams JE, Genant HK. Diagnosis and classification of vertebral fractures. In: Rosen CJ, Bouillon

R, Compston JE, Rosen V. editors. Primer on the metabolic bone diseases and disorders of mineral metabolism. Philadelphia, PA: Wiley-Blackwell, 2013:317-35.

13. Lentle B, Koromani F, Brown JP, Oei L, Ward L, Goltzman D, Rivadeneira F, Leslie WD, Probyn L, Prior J, Hammond I, Cheung A, Oei E. The radiology of osteoporotic vertebral fractures revisited. J Bone Miner Res 2019;34:409-18.

14. Genant HK, Wu CY, van Kuijk C, Nevitt MC. Vertebral fracture assessment using a semiquantitative technique. J Bone Miner Res 1993;8:1137-48.

15. Link TM. Radiology of Osteoporosis. Can Assoc Radiol J 2016;67:28-40.

16. Kendler DL, Bauer DC, Davison KS, Dian L, Hanley DA, Harris ST, McClung MR, Miller PD, Schousboe JT, Yuen CK, Lewiecki EM, Vertebral fractures: clinical importance and management. Am J Med 2016;129:221.e1-10.

17. Schousboe JT, Vokes T, Broy SB, Ferrar L, McKiernan F, Roux C, Binkley N. Vertebral Fracture Assessment: the 2007 ISCD Official Positions. J Clin Densitom 2008;11:92-108.

18. Jiang G, Eastell R, Barrington NA, Ferrar L. Comparison of methods for the visual identification of prevalent vertebral fracture in osteoporosis. Osteoporos Int 2004;15:887-96.

19. Lentle BC, Berger C, Probyn L, Brown JP, Langsetmo L, Fine B, Lian K, Shergill AK, Trollip J, Jackson S, 
Leslie WD, Prior JC, Kaiser SM, Hanley DA, Adachi JD, Towheed T, Davison KS, Cheung AM, Goltzman D; CaMos Research Group. Comparative Analysis of the Radiology of Osteoporotic Vertebral Fractures in Women and Men: Cross-Sectional and Longitudinal Observations from the Canadian Multicentre Osteoporosis Study (CaMos). J Bone Miner Res 2018;33:569-79.

20. Oei L, Rivadeneira F, Ly F, Breda SJ, Zillikens MC, Hofman A, Uitterlinden AG, Krestin GP, Oei EH. Review of radiological scoring methods of osteoporotic vertebral fractures for clinical and research settings. Eur Radiol 2013;23:476-86.

21. Lentle B, Trollip J, Lian K. The radiology of osteoporotic vertebral fractures redux. J Clin Densitom 2016;19:40-7.

22. Kleerekoper M. The evaluation of patients with osteoporosis. In: Marcus R, Feldman D, Kelsey J. editors. Osteoporosis. San Diego, CA: Academic Press, 1966:1101-8.

23. Deng M, Zeng XJ, He LC, Leung JCS, Kwok AWL, Griffith JF, Kwok T, Leung PC, Wáng YXJ. Osteoporotic vertebral fracture prevalence in elderly Chinese men and women: a comparison of endplate/cortex fracture-based and morphometrical deformity-based methods. J Clin Densitom 2019;22:409-19.

24. Wáng YXJ, Che-Nordin N, Deng M, Leung JCS, Kwok AWL, He LC, Griffith JF, Kwok TCY, Leung PC. Osteoporotic vertebral deformity with endplate/cortex fracture is associated with higher further vertebral fracture risk: the Ms. OS (Hong Kong) study results. Osteoporos Int 2019;30:897-905.

25. Oei L, Koromani F, Breda SJ, Schousboe JT, Clark EM, van Meurs JB, Ikram MA, Waarsing JH, van Rooij FJ, Zillikens MC, Krestin GP, Oei EH, Rivadeneira F. Osteoporotic vertebral fracture prevalence varies widely between qualitative and quantitative radiological assessment methods: the Rotterdam Study. J Bone Miner Res 2018;33:560-8.

26. Wáng YX, Santiago FR, Deng M, Nogueira-Barbosa MH. Identifying osteoporotic vertebral endplate and cortex fractures. Quant Imaging Med Surg 2017;7:555-91.

27. Leidig-Bruckner G, Limberg B, Felsenberg D, Bruckner T, Holder S, Kather A, Miksch J, Wüster C, Ziegler R, Scheidt-Nave C. Sex difference in the validity of vertebral deformities as an index of prevalent vertebral osteoporotic fractures: a population survey of older men and women. Osteoporos Int 2000;11:102-9.

28. Szulc P, Munoz F, Marchand F, Delmas PD. Semiquantitative evaluation of prevalent vertebral deformities in men and their relationship with osteoporosis: the MINOS study. Osteoporos Int 2001;12:302-10.

29. Lauridsen KN, De Carvalho A, Andersen AH. Degree of vertebral wedging of the dorso-lumbar spine. Acta Radiol Diagn (Stockh) 1984;25:29-32.

30. Matsumoto M, Okada E, Kaneko Y, Ichihara D, Watanabe K, Chiba K, Toyama Y, Fujiwara H, Momoshima S, Nishiwaki Y, Hashimoto T, Takahata T. Wedging of vertebral bodies at the thoracolumbar junction in asymptomatic healthy subjects on magnetic resonance imaging. Surg Radiol Anat 2011;33:223-8.

31. Kherad M, Rosengren BE, Hasserius R, Nilsson JÅ, Redlund-Johnell I, Ohlsson C, Lorentzon M, Mellström D, Karlsson MK. Low clinical relevance of a prevalent vertebral fracture in elderly men--the MrOs Sweden study. Spine J 2015;15:281-9.

32. Wáng YXJ, Che-Nordin N, Deng M, Griffith JF, Leung JCS, Kwok AWL, Leung PC, Kwok TCY. Elderly males with or without existing osteoporotic vertebral fracture have much lower future vertebral fracture risk than elderly females: the MrOs (Hong Kong) year-4 followup spine radiograph study. Osteoporosis International 2019;30:2505-14,

33. Lentle BC, Brown JP, Probyn L, Hammond I, Hu J, Fine B, Lian K, Shergill A, Trollip J, Berger C, Leslie WD, Prior JC, Hanley DA, Adachi JD, Josse RG, Cheung AM, Davison KS, Kaiser SM, Towheed T, Kovacs CS, Wong AK, Goltzman D. Low-grade vertebral deformities result from historical events and are unlikely to be primarily osteoporotic in provenance (abstract). J Bone Miner Res 2018;33:387.

34. Lentle BC, MD, Brown J, Khan A, Leslie WD, Lévesque J, MD, Lyons DJ, Siminoski K, Tarulli G. The recognition and reporting of vertebral fractures: a powerful tool to reduce the risk of future osteoporotic fractures. Can Assoc Radiol J 2007;58:27-36.

35. Lentle B, Hammond I. The radiology of osteoporosis. Can Assoc Radiol J 2017;68:342-3.

36. Wáng YX, Wang XR, Che-Nordin N, Xu FR, Huang QL. On the possibility of over-diagnosis of osteoporotic vertebral fracture at mid-thoracic level. J Thorac Dis 2019;11:5708-11.

37. Yakemchuk V, Beaumont LF, Webber CE, Gulenchyn KY, Jager PL. Vertebral fracture prevalence in a referral population of 750 Canadian men and women. Clin Radiol 2012;67:1061-8.

38. Ferrar L, Jiang G, Armbrecht G, Reid DM, Roux C, Glüer 
CC, Felsenberg D, Eastell R. Is short vertebral height always an osteoporotic fracture? The Osteoporosis and Ultrasound Study (OPUS). Bone 2007;41:5-12.

39. Wáng YXJ, Santiago FR, Deng M, Nogueira-Barbosa MH. Identifying osteoporotic vertebral endplate and cortex fractures. Quant Imaging Med Surg 2017;7:555-91.

40. Wáng YX, Deng M, He LC, Che-Nordin MN, Santiago RF Osteoporotic vertebral endplate and cortex fractures: a pictorial review. J Orthop Translat 2018;15:35-49.

41. Wáng YX. A modified semi-quantitative (mSQ) grading scheme for osteoporotic vertebral fracture in elderly women. Quant Imaging Med Surg 2019;9:146-50.

42. Diacinti D, Giuseppe Guglielmi G. How to define an osteoporotic vertebral fracture? Quant Imaging Med Surg 2019;9:1485-94.

Cite this article as: Lentle BC. Gender and the recognition of vertebral fractures. Quant Imaging Med Surg 2020;10(6):1401-1407. doi: 10.21037 /qims.2020.04.12 